\title{
Hazard from soil contamination in the gold mining district of Kedougou (Senegal, Africa)
}

\author{
M. THIOMBANE ${ }^{1}$, B. De VIVO ${ }^{2}$, B. NIANE ${ }^{3}$, M.J.
} WATTS $^{4}$, A.L. MARRIOTT ${ }^{4}$, M. Di BONITO ${ }^{5 *}$

${ }^{1}$ DiSTAR, University of Naples “Federico II", Napoli, Italy.

${ }^{2}$ Pegaso University, Piazza Trieste e Trento 48, Naples, Italy.

${ }^{3}$ Ministère des Mines et de la Géologie, Keur Gorgui, Im. Aye Mariétou Fall, Dakar, Senegal.

${ }^{4}$ Centre for Environmental Geochemistry, British Geological Survey, Keyworth NG12 5GG, UK.

${ }^{5}$ ARES, Nottingham Trent University, NG25 0QF, UK. (*correspondence: marcello.dibonito@ntu.ac.uk)

\section{Background and methods}

Our study aimed to detect and discriminate anthropogenic versus geogenic elemental enrichment in soils of the Kedougou region (Senegal). Ninety-four soil samples were collected over an area of $6,742 \mathrm{~km}^{2}$ and analysed by ICP-MS for 53 elements. Mapping and geostatistical methods were used to identify elemental footprints associated with mineralisations and mining activities. Multivariate methods (fractal plots, regression plot and robust factor analysis) together with interpretative indicies (Enrichment factor -EFs- Index of Geoaccumulation -IGeo- and the robust compositional contamination index - RCCI) were used to interpret variables correlation and the underlying geochemical processes.

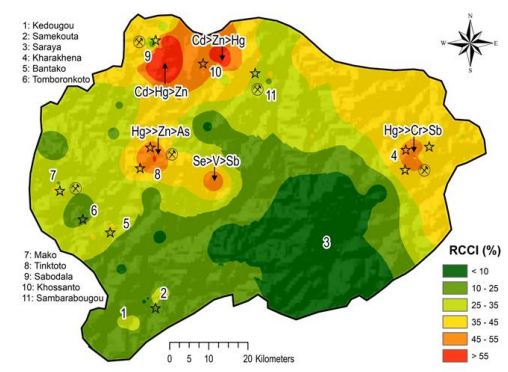

Figure 1. RCCI Interpolated map of the 15 considered Potentially Harmful Elements (PHEs).

\section{Discussion of Results}

Discrete areas of significant contamination levels corrensponding to Artisanal Scale Gold Mining (ASGM) activities were established, highlighting the importance of complementary approaches to identify contamination related to potentially harmful elements (PHE). These areas need further and more detailed investigation to achieve a comprehensive human and ecological risk assessment. 